\author{
H. De Boeck • P. Opdecam
}

\title{
Split coronal fractures of the lumbar spine
}

\section{Treatment by posterior internal fixation and transpedicular bone grafting}

\author{
Accepted: 1 December 1998
}

\begin{abstract}
The clinical and radiological results of 12 patients with a split coronal vertebral fracture were analysed with minimum follow-up of 24 months. All patients were treated operatively with an $\mathrm{AO}$ internal spinal fixator and transpedicular bone grafting. The operation was supplemented with posterior bone grafts in 4 patients. All fractures healed without marked deformity. There were no vertebral body pseudarthroses. There were no neurological or vascular injuries due to the placement of pedicle screws or to transpedicular bone grafting. $10 \mathrm{pa}-$ tients, had excellent or good results.

Résumé Les résultats cliniques et radiologiques de douze patients victimes d'une fracture du corps vertébral à trait frontal ont été analysé. Tous les patients avaient été opérés suivant la même technique: fixation interne de 1'AO associé à une greffe osseuse transpédiculaire. Quatre de ces patients ont bénéficié en outre d'une greffe osseus postérieure. Toutes les fractures ont consolidées sans déformation marquante. Il n'y a pas de pseudarthrose du corps vertébral. Il n'y a pas eu de troubles neurologiques ou vasculaires dûs aux vis pédiculaires ou à la greffe transpédiculaire. Sur un suivi de minimum 24 mois, dix des douze patients ont un résultat classé excellent ou bon.
\end{abstract}

\section{Introduction}

Impaction injury of the vertebral body resulting in a split fracture in the frontal plane is classified by Gertzbein as Type A2 (split coronal) fracture [8]. This fracture-type with the main fragment displaced anteriorly has received little attention in the past. The purpose of this study was to determine the clinical outcome and radiographic findings for patients with a type A2 lumbar fracture treated with $\mathrm{AO}$ internal fixator and transpedicular bone grafting.

H. De Boeck ( P. Opdecam

Department of Orthopaedic Surgery and Traumatology, University Hospital V.U.B., Laarbeeklaan 101, B-1090 Brussels, Belgium Tel.: +32-2-477 6547

Fax: +32-2-477 6505

\section{Patients and methods}

From 1992 to 1996,12 patients with a split coronal fracture, type A2 according to Gertzbein [8] at the lumbar level were treated operatively using a posterior approach. Preoperative evaluation for all patients included plain radiography and computerized tomography. In two patients additional lateral tomograms were made. In

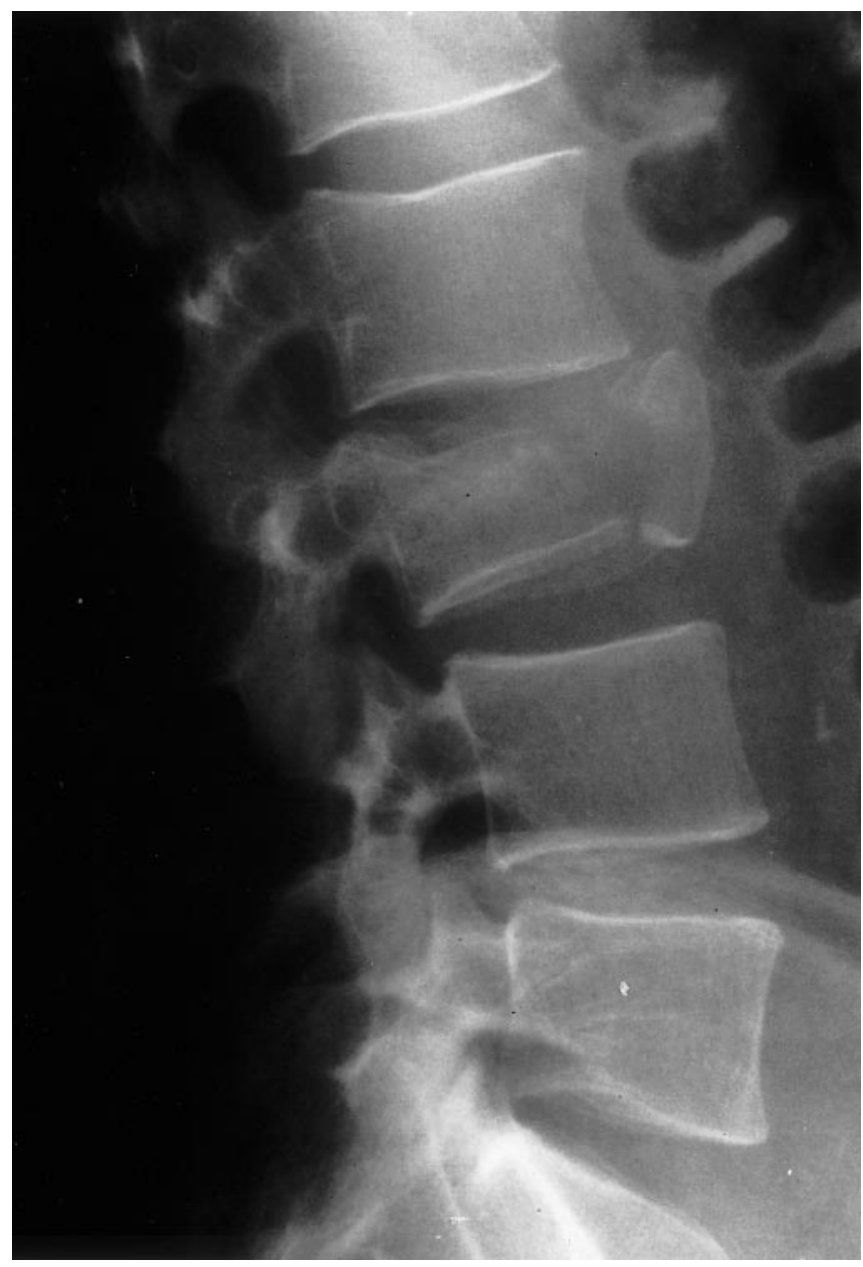

Fig. 1 Lateral roentgenogram at admission showing a split coronal fracture of L3 with a fracture line in the frontal plane 
Table 1 Data on the patients

\begin{tabular}{|c|c|c|c|c|c|c|c|c|c|c|}
\hline Case & Sex & $\begin{array}{l}\text { Age } \\
\text { (yrs) }\end{array}$ & Mode of Injury & $\begin{array}{l}\text { Level of } \\
\text { Injury }\end{array}$ & $\begin{array}{l}\text { Duration of } \\
\text { Follow-up } \\
\text { (months) }\end{array}$ & \multicolumn{2}{|c|}{ Neurological grade* } & $\begin{array}{l}\text { Works status** } \\
\begin{array}{l}\text { Duration until } \\
\text { return to work (Mos) }\end{array}\end{array}$ & \multicolumn{2}{|c|}{$\begin{array}{l}\text { Pain at latest } \\
\text { follow-up*** }\end{array}$} \\
\hline 1 & M & 44 & Fall & L3 & 27 & $\mathrm{C}$ & $\mathrm{E}$ & OW/14 & 0 & 0 \\
\hline 4 & $\mathrm{~F}$ & 53 & Fall & L1 & 35 & $\mathrm{D}$ & $\mathrm{E}$ & OW/6 & 0 & 1 \\
\hline 5 & M & 60 & Fall & L4 & 28 & $\mathrm{E}$ & $\mathrm{E}$ & MW/10 & 0 & $1+$ \\
\hline 6 & M & 27 & Fall & L1 & 24 & $\mathrm{E}$ & $\mathrm{E}$ & MW/12 & 1 & 0 \\
\hline 7 & M & 43 & Fall & L3 & 40 & $\mathrm{E}$ & $\mathrm{E}$ & $\mathrm{LW} / 12$ & 1 & $1+$ \\
\hline 10 & $\mathrm{~F}$ & 32 & $\begin{array}{l}\text { Automobile } \\
\text { accident }\end{array}$ & L3 & 52 & $\mathrm{E}$ & $\mathrm{E}$ & $\mathrm{NR} /-$ & 2 & 1 \\
\hline 11 & M & 48 & Fall & L3 & 55 & $\mathrm{E}$ & $\mathrm{E}$ & MW/10 & 0 & 0 \\
\hline 12 & M & 30 & Fall & L1 & 60 & $\mathrm{E}$ & $\mathrm{E}$ & MW/12 & 1 & 0 \\
\hline
\end{tabular}

* According to Frankel et al. C: sensation present, motor function not useful, D: sensation present; motor function weak but useful, E: neurologically intact

** OW=return to original work, $\mathrm{NR}=$ no return to work, $\mathrm{MW}=$ modified work

*** $\mathrm{O}=$ no pain, $1=$ mild occasional pain requiring no medication and not interfering with work, $2=$ moderate pain, necessitating occasional medication or limitation of activity, $3=$ constant pain

+: Local pain due to concomitant fracture of the lower limb. This score was not taken into account for assessment of the final results

Table 2 Radiographic evaluation. A Admission; $P O$ post-operative; $F U$ latest follow-up

\begin{tabular}{|c|c|c|c|c|c|c|c|}
\hline \multirow[t]{2}{*}{ Case } & \multicolumn{3}{|c|}{$\begin{array}{l}\text { Anterior compression } \\
\text { angle (degrees) }\end{array}$} & \multicolumn{3}{|c|}{$\begin{array}{l}\text { Sagittal index } \\
\text { (degrees) }\end{array}$} & \multirow{2}{*}{$\begin{array}{l}\text { Time to } \\
\text { radiographic } \\
\text { union } \\
\text { (Mos) }\end{array}$} \\
\hline & $\mathrm{A}$ & $\mathrm{PO}$ & FU & A & $\mathrm{PO}$ & $\mathrm{FU}$ & \\
\hline 1 & 0 & 0 & 4 & 18 & 0 & 13 & 14 \\
\hline 2 & 14 & 8 & 7 & 20 & -2 & 8 & 6 \\
\hline 3 & 0 & 0 & 0 & 1 & -2 & 2 & 18 \\
\hline 4 & 30 & 8 & 2 & 30 & 8 & 15 & 8 \\
\hline 5 & 2 & 0 & 0 & 0 & -10 & -10 & 10 \\
\hline 6 & 12 & 4 & 6 & 10 & 4 & 8 & 6 \\
\hline 7 & 8 & 0 & 2 & 20 & 4 & 6 & 10 \\
\hline 8 & 3 & 0 & 0 & 10 & -2 & 0 & 8 \\
\hline 9 & 10 & 4 & 5 & 15 & 8 & 10 & 8 \\
\hline 10 & 2 & 6 & 2 & 2 & 0 & 2 & 10 \\
\hline 11 & 8 & 0 & 2 & 18 & 5 & 8 & 8 \\
\hline 12 & 12 & 4 & 5 & 14 & 6 & 8 & 8 \\
\hline
\end{tabular}

all patients, the major fracture line was located in the anterior half of the vertebral body, running in the frontal plane from the upper end plate to the lower end plate. The ventral part of the fracture was displaced anteriorly (Fig. 1). The first lumbar level was involved three times, the second level twice, the third level five times and the fourth level twice.

There were 10 men and 2 women whose age ranged from 24 to 59 years (mean 43 years). All patients had a single level vertebral fracture. Five patients had associated fractures.

Neurological status was graded according to the criteria developed by Frankel and associates [6]. The average follow-up for all patients was 38 months (range 24 to 60 months). All patients were evaluated for pain and work ability.
All patients were assessed clinically and radiograghically (Tables 1, 2). The anterior compression angle of Denis [4], and the segmental kyphosis at admission, after operation and at latest follow-up were measured on a lateral radiograph. Segmental kyphosis at the level of the fracture (one vertebra and the superior disc) was measured as the lateral Cobb angle and evaluated in terms of the sagittal index ( S I).

Kyphotic deformity was defined as a positive measurement. S I was evaluated as the segmental kyphosis minus baseline sagittal curve $\left(0^{\circ}\right.$ for $\mathrm{L} 1$ and $-10^{\circ}$ for the lower lumbar segments) according to Farcy et al. [5]. The time to complete radiographic union was recorded. Results were rated as excellent, good, fair or poor according to the evaluation criteria shown in Table 3. 
Table 3 Evaluation parameters

\begin{aligned} \hline Excellent: & - no pain \\ & - no neurologic deterioration \\ & - return to original work \\ & - radiographic evidence of fracture healing \\ & - maximum 15 degrees of SI \\ & - maximum 6 degrees of anterior compression angle \\ Good: $\quad$ - no pain or occasional pain & \\ & - no neurological deterioration \\ & - return to original work or modified work \\ & - maximum 20 degrees of SI \\ & - maximum 10 degrees of anterior compression angle \end{aligned}

If one of the above criteria, for good results were not met (with the exception of neurological deterioration or fracture healing) the results were rated as fair. Any case where no fracture healing was obtained or with neurological deterioration was graded as poor

\section{Operative technique}

All operations were performed by the first author (H.D.B.). The average time from the injury to the operation was 2 days (range 1 to 4 days). Antibiotic prophylaxis with a cephalosporin was used routinely. Patients were placed in the prone position on bolsters. The spine was exposed through a standard posterior approach. Under fluor-

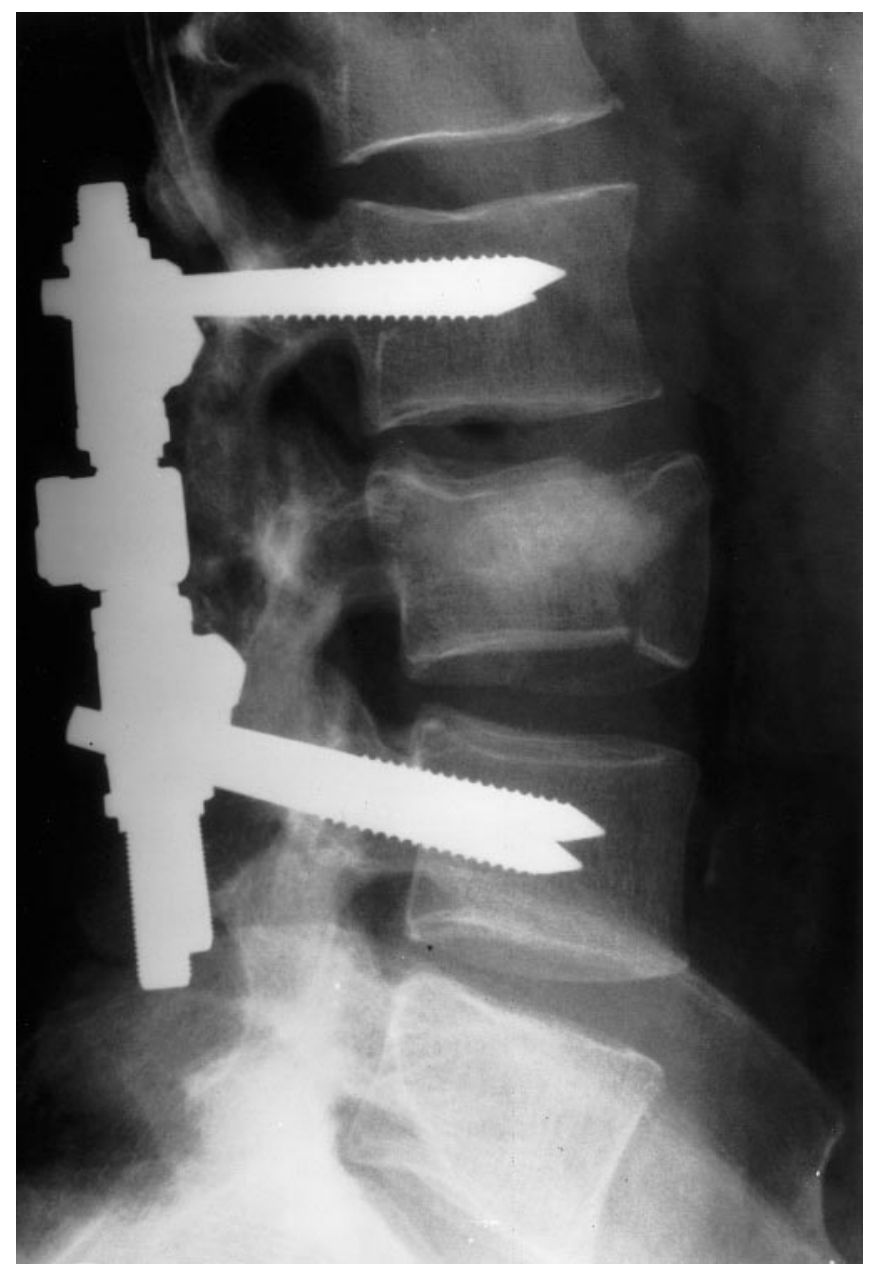

Fig. 2 Standing roentgenogram taken after operation. The bone grafts, bridging the fracture line are visible oscopic control $6.0 \mathrm{~mm}$ Schanz screws were inserted into the pedicles of the vertebra above and below the fractured vertebra. The Schanz screws were connected to the internal fixator with the specially designed clamps. The instrumented spinal segments were lordosed if necessary and distracted. Ligamentotaxis was achieved by distraction along the threated longitudinal rods between the Schanz screws. Partial reduction of the antepulsed fragment could be obtained this way. The Schanz screws were then secured to the clamps by tighthening the clamp nuts. The intramedullary canal of the pedicle of the fractured vertebra was located using a probe. The probe was advanced by manually guiding it down the intramedullary canal of the pedicle into the vertebral body. After withdrawing the probe, a $7.0 \mathrm{~mm}$ Schanz screw connected to a T-handle was used to create a hole in both pedicles of the fractured vertebra. The Schanz screw was advanced manually through the pedicle into the vertebral body under fluorscopic control until the tip of the Schanz screw touched the anterior bone fragment. Particular attention was paid at this stage to ensure that the screw did not push the ventral bone fragment further anteriorly. After removal of the screw, the hole in the pedicle and in the vertebral body could be enlarged further with small curettes, taking care to preserve the walls of the pedicle. Removal of disc and endplate particles from the fracture gap through the pedicles was possible with small forceps and small curettes. Cancellous bone graft was obtained from the posterior aspect of the iliac crest with an acetabular reamer. Through the special designed funnel [2] inserted in the pedicle, the autogenous cancellous bone, in the form of bone paste was inserted in the fracture gap, creating a bone continuity between the fragments of the vertebral body (Fig. 2). A cross-link system between the 2 threated rods was used to stabilize the internal fixator.



Fig. 3 Standing roentgenogram made 18 months postinjury demonstrating radiographical union 
Postoperatively all patients were fitted with a light-weight threepoint corset for three months. The patients were mobilized 3 to 4 days postoperatively and started physical therapy. Patients underwent removal of metalwork between 9 and 16 months after surgery.

\section{Results}

All fractures showed radiological union at the latest follow-up (Fig. 3). The average anterior compression angle was 2.9 degrees; none exceeding 7 degrees. Average S I was 6.7 degrees none exceeding 15 degrees. The average time of radiological union was 9.5 months (range 6 to 18 months). No patients had deterioration of neurological function and 2 patients who had a neurological deficit improved by 1 grade and another patient improved by 2 grades. Ten patients returned to their prevous employment. Five patients resumed a physically less demanding job than before the injury. Two patients did not return to work.

\section{Discussion}

Split coronal fractures are well recognized but should be distinguished from the true burst fracture and from the simple anterior wedge compression fracture. There are few reports on these injuries. Roy-Camille and Lelièvre proposed that this type of fracture should be treated operatively by posteriorly placed plates with pedicle screw fixation [9].

Normally, the fracture will heal irrespective of the type of treatment. Pseudarthrosis of the vertebral body is unusual after conservative treatment. In translated fractures with poor or absent apposition of the fracture fragments satisfactory fracture healing may not occur $[1,3]$. Gaines and Humphreys state that in these cases bone healing will not occur without surgical treatment [7]. The split coronal fracture is an example of such a situation where a vertebral body pseudarthrosis may result if treated conservatively.

The mechanism of this fracture is compression by axial load. It is a combination of crush and cleavage. The fracture is characterized by superior disc injury, a crush fracture of the upper end plate and coronal cleavage fracture of the vertebral body. Disc material as well as end plate fragments are driven between the two main fragments and the ventral part of the vertebral body is pushed anteriorly (Fig. 1). The exact incidence of pseuarthrosis after this fracture type is not known. Persistant pain after conservative treatment may be caused by undiagnosed pseudarthrosis [9].
The goal of treatment is to obtain union by stabilizing the fracture, removing fragments of disc from between the bone fragments and creating bony continuity betwen the rest of the vertebral body and the anteriorly displaced fragment. This can be achieved through a posterior route with transpedicular bone grafting combined with a rigid internal fixation (Fig. 2).

The split coronal fracture is distinct from the true burst fracture and the aim of the operative treatment in our group of patients was to promote bone healing by filling the fracture gap with cancellous bone after removal of interposed tissue. The technique of transpedicular grafting is not difficult but attention to detail in technique is important. Careful control of the intramedullary canal of the pedicle is necessary and great care has to be taken to prevent fracture of the pedicle when the funnel is introduced.

Although the number of patients is small in this series, we conclude that the split coronal fracture can be treated succesfully with posterior short-segment instrumentation and transpedicular bone grafting.

\section{References}

1. Bedbrook GM, Hon OBE (1975) Treatment of thoracolumbar dislocation and fractures with paraplegia. Clin Orthop 112: 27-43

2. Daniaux H (1986) Transpedikuläre Reposition and Spongiosaplastik bei Wirbelkörperbrüchen der unteren Brust- und Lendenwirbelsäule. Unfallchirurg 89:197-213

3. Davies WE, Morris JH, Hill V (1980) An analysis of conservative (nonsurgical) management of thoracolumbar fratures and fractures-dislocations with neural damage. J Bone Joint Surg [Am] 62:1324-1328

4. Denis F, Ruiz H, Searls K (1984) Comparison between squareended distraction rods and standard round-ended distraction rods in the treatment of throacolumbar spinal injuries. A statistical analysis. Clin Orthop 189:162-167

5. Farcy JPC, Weidenbaum M, Glassman SD (1990) Sagittal index in management of thoracolumbar burst fractures. Spine 15:958-965

6. Frankel HL, Hancock DO, Hyslop G, Melzak J, Michaelis LS, Ungar GH, Vernon JDS, Walsh JJ (1969) The value of postural reduction in the initial management of closed injuries of the spine with paraplegia and tetraplegia. Part I. Paraplegia 7: 179-192

7. Gaines RW, Humphreys WG (1984) A plea for judgement in management of thoracolumbar fractures and fracture-dislocations. A reassessment of surgical indications. Clin Orthop 189: $36-41$

8. Gertzbein SD (1994) Spine update. Classification of thoracic and lumbar fractures. Spine 19:626-628

9. Roy-Camille R, Lehèvre JF (1975) Pseudarthrose des corps vertébraux du rachis dorso-lombaire. Rev Chir Orthop 61: 249-257 